\title{
A historiografia escolar na Comissão Nacional do Livro Didático: pareceres de Jonathas Serrano (1938/1941)
}

Itamar Freitas ${ }^{1}$

\section{RESUMO}

Este artigo examina rotinas da Comissão Nacional do Livro Didático (1941), buscando respostas para questões bastante recorrentes na pesquisa sobre a história do ensino de história no Brasil: o que é ser didático? Quais os traços dominantes na produção da historiografia destinada à comunidade escolar? Quais os critérios utilizados na avaliação do livro do aluno na administração do Ministro Gustavo Capanema? o objeto de análise são os pareceres do professor e historiador Jonathas Serrano (1885/1944) - catedrático do Colégio Pedro II e da Escola Normal do Distrito Federal e sócio do IHGB -, elaborados no primeiro ano de vigência da referida Comissão.

Palavras-chave: livro didático, Comissão Nacional do Livro Didático, ensino de história, historiografia escolar, Jonathas Serrano, ensino secundário.

0 fenômeno da "consolidação" da história como disciplina escolar do secundário no período 1931 e 1942 já é consenso entre os historiadores da educação. 0 argumento de que o tempo circunscrito nas reformas Francisco Campos e Gustavo Capanema representa um divisor de águas para a história ensinada ganha força no fato de a História do Brasil ter voltado ao currículo (1942) como disciplina independente. Também pesou nesse consenso, notadamente, a manutenção/ ampliação do espaço dedicado ao saber de Clio nos estudos secundários, seja num currículo de caráter cientificista, seja numa grade de face humanista - como o foram, respectivamente, as duas citadas prescrições.

Além desses condicionantes, seria importante acrescentar a criação de uma certa pedagogia da (ou para o ensino de) história a ser disseminada por

\footnotetext{
1 Doutorando em História da Educação (PUC/SP). Professor de historiografia brasileira e teoria da história na Universidade Federal do Sergipe (UFS). E-mail: itamarfreitas@bol.com.br.
} 
todo o Brasil, na esteira do processo de uniformização do ensino secundário (HOLLANDA, 1957; SILVA, 1959; ANTUNHA, 1993). Nessa pedagogia, constava também como fundamental a uniformização dos livros escolares. E o governo da União tratou de provê-la, estabelecendo, mediante decreto-lei, em fins de 1938, "as condições de produção, importação e utilização do livro didático" no país. (Decreto-Lei n. 1006, 30 set. 1938).

Não era "a primeira vez que se faz[ia] a seleção rigorosa de livros didáticos no Brasil", como noticiou-se em 1941. Os governos estaduais encarregaram-se da tarefa antes mesmo da União. Claro que as iniciativas paulistas, por exemplo, ocorridas de 1907 em diante (CARDIM et al, 1908), contemplavam apenas os livros destinados ao ensino primário - livros de leitura e livros de matéria. Os livros empregados na Escola Normal da Praça e no Colégio São Paulo eram indicados pelos catedráticos e submetidos ao crivo das respectivas congregações. Mas, a partir de 1910, pode-se perceber um aumento na teorização sobre o conceito e o emprego desse recurso pedagógico, culminando com uma refinada proposta de triagem a cargo da comissão formada por Sampaio Dória (relator), Américo Moura e Plínio Barreto em 1917. (THOMPSON, 1910; CHINA, 1913; REIS JÚNIOR, 1915; ALVES, 1917; DóRIA et al, 1917). A grande diferença da iniciativa federal, entretanto, estava na sua esfera de abrangência e do poder normatizador. As decisões tomadas pela Comissão Nacional do Livro Didático - CNLD deveriam ser respeitadas em todo o Brasil, e a sua competência somente não alcançaria o ensino superior.

É por isso que se pode vislumbrar a CNLD como fator de modificação de alguns aspectos do ensino secundário. Se, antes da reforma Campos (1931), os valores epistemológicos e morais de cada professor - filtrados nos programas de ensino - formatavam o livro didático, é muito provável que, depois das prescrições da década de 1930, inversamente, os impressos tenham dado a direção das aulas, com todo o seu arsenal de ilustrações, quadros sinópticos e sincrônicos, cronologias, exercícios e, principalmente, as "orientações metodológicas", prescritas pelo governo da União. (FREITAS, 2004, p. 214).

Este texto, entretanto, não faz a crítica das políticas públicas sobre o livro didático, nem avalia o grau de intervenção do governo federal, tampouco aponta os precursores em tal sentido. ${ }^{2}$ Aqui se promove, somente, uma

2 Um comentário sobre a ação da CNLD nos anos 1950 e a crítica aos dispositivos legais de criação e instalação da Comissão - truísmos, falhas de redação, intromissão na esfera de competência dos Estados e dos 
prospecção nas rotinas da Comissão Nacional do Livro Didático, buscando respostas para questões bastante debatidas pelos pesquisadores da área: o que é ser didático em se tratando do ensino de história? Quais os "segredos internos" da historiografia destinada à comunidade escolar?

O objeto de análise são os pareceres elaborados pelo professor e historiador Jonathas Serrano - catedrático do Colégio Pedro II e da Escola Normal do Distrito Federal -, durante o primeiro ano de vigência da referida Comissão. Antes de tratar dos pareceres, saibamos um pouco mais sobre a criação e 0 funcionamento dessa instância prescritiva.

\section{A Comissão Nacional do Livro Didăuco}

O Decreto-lei que normatizava a produção, circulação e uso do livio didático no Brasil, documento fundador da CNLD, definia de início o gênero "livro didático" em duas espécies singulares: o compêndio, que expunha "total ou principalmente a matéria das disciplinas constantes dos programas escolares", e o livro de leitura, "utilizado para a leitura dos alunos em sala de aula". O mesmo dispositivo deixava a escolha dos livros didáticos a cargo dos professores - obviamente, entre aquelas obras autorizadas pela Comissão. Também liberava os mestres quanto ao "processo de utilização dos livros adotados", mas fazia uma intervenção significativa no modo de ensinar ao proibir o "ditado de lições constantes dos compêndios ou o ditado de notas relativas a pontos dos programas escolares". O governo queria extirpar, por decreto, uma prática escolar que, mesmo no secundário francês daquela época, era abonada pela maioria dos professores. 0 esperado era que tudo isso vigorasse a partir de $1^{\circ}$ de janeiro de 1940. (Decreto-lei n. 1006, 30 set. 1938).

Mas, quais seriam os juízes? E quanto aos critérios de seleção? Na primeira menção ao problema, o Decreto-lei n. 1006 determinava a convocação de "pessoas de notório preparo pedagógico e de reconhecido valor moral." (idem, Cap. II, art. 9). Cinco meses depois, a CNLD ganhava forma: seriam dezesseis membros e não mais sete, como previa o decreto fundador; e o mais importante,

municípios, o espírito "anti-regional" e "centralizador", podem ser acompanhadas no capítulo XIII do clássico livro de Guy de Hollanda (1957): Um quarto de século de programas e compêndios de história para o ensino secundário brasileiro: 1931/1956. 
julgo: de "especialistas em metodologia" - das línguas (2), ciências (3) e técnicas (2) - requeria-se, agora, a presença do "especialista nos vários assuntos do ensino pré-primário, primário, normal, profissional e secundário". (Decretolei n. 1177, 29 mar. 1939).

Não se pode afirmar se tal critério foi ou não cumprido à risca. Mas, a comissão designada pelo presidente da República compôs-se, certamente, por figuras de escol - como se dizia à época - destacados nos debates sobre 0 mesmo secundário, inclusive dos anos 1920: Abgar Renault, Alvaro Ferdinando de Souza da Silveira, Armando Pinna, Waldemar Pereira Cota, Maria Junqueira Schmidt, Antonio Carneiro Leão, Jonathas Archanjo da Silveira Serrano, Leonel Franca, Rodolpho Fuchs, Arthur Torres Filho, Euclides de Medeiros Guimarães Roxo e Carlos Delgado de Carvalho.

Ocorre que 0 ano de 1939 se extinguira, 0 dia final havia chegado $-01^{\circ} \mathrm{de}$ janeiro de 1940 -, e a Comissão não dera conta do trabalho, segundo a voz do próprio Executivo. A solução encontrada foi 0 relaxamento dos prazos: a CNLD funcionaria até 31 de dezembro de 1940 e a data-limite para a adoção dos livros autorizados seria o $1^{\circ}$ de janeiro de 1941. (Decreto-lei n. 2359, 3 jul. 1940).

Não acreditamos que a comissão tenha descurado das suas tarefas. É provável que não tenha trabalhado, efetivamente, no período 1939/1940. 0 que alimenta essa hipótese é a emissão de portaria do Ministério da Educação e Saúde baixando "instruções para o funcionamento" da mesma. ${ }^{3}$ (Portaria n. 253, 24 dez. 1940). Esse mesmo dispositivo, ao final do ano 1940, que dava vida à CNLD, também codificava 0 rito de seleção, que se iniciava com a entrega dos originais à Comissão. Das mãos do presidente do órgão, o livro era repassado a um relator e a dois revisores, membros da secção relativa à matéria compendiada pelo livro - secção de línguas e literaturas; matemática e desenho; ciências físicas e naturais; geografia; história; filosofia; sociologia e pedagogia; metodologia das técnicas; e matérias do ensino primário. 0 relator teria 30 dias, contados a partir do recebimento, para emitir o seu parecer. Aos revisores, concedia-se o prazo de 15 dias. Depois dos especialistas, seria a vez da seção de redação estabelecer o seu julgamento, "negando", "concedendo" ou indicando modificações na obra. Os pareceres seriam levados a plenário, a quem caberia a decisão final.

3 Isso explica também a ampliação do prazo final de circulação de livros didáticos não autorizados pelo Ministério da Educação, de 1 de janeiro de 1941 para 1 de janeiro de 1942. (Decreto-lei n. 2934, 31 dez. 1940). 
Jonathas Serrano, como vimos, foi guindado à condição membro em 1930, como especialista da seção de história. Academicamente, estaria respaldado pelo trabalho desenvolvido na Escola Normal do Rio de Janeiro, como professor e administrador, desde 1916. No Colégio Pedro II, fora catedrático de história universal a partir de 1926, além de ter escrito obras pedagógicas para professores - Metodologia da bistória na aula primária (1917), A escola nova (1932), Como se ensina bistória (1936) - para os alunos do ensino primário e secundário - Epitome de bistória universal (1915), História do Brasil (1931) e História da civilização (1935) em vários volumes e séries. É preciso registrar, contudo, a condição de católico militante e de homem próximo a Lourenço Filho e Gustavo Capanema. Isso, certamente, contou bastante para a sua inclusão no seleto grupo que ditaria 0 padrão do novo didático brasileiro.

\section{Os pareceres de Jonathas Serrano}

Qual o formato de um parecer? Os documentos são breves. Ocupam de duas a três folhas, datilografadas em espaço $1,5 \mathrm{~cm}$. Encimada pelo cabeçalho, "Comissão Nacional do Livro Didático/Secção História", a primeira página consta do número do processo, nome do autor, da obra, edição, editor, cidade, ano de publicação e do veredicto: pode ou não pode ser autorizada como livro didático, segundo a legislaçã̃o vigente.

Já foi mencionado que o decreto fundador da CNLD prescrevia os elementos a serem avaliados: linguagem, informaçoes de natureza científica ou técnica, e o emprego dos preceitos fundamentais da pedagogia e das normas didáticas oficialmente adotadas. (Dec.-Lei n. 1006, 30 set. 1928, art. 21). 0 parecer, contudo, não segue, necessariamente, a essa ordem. Mas, no geral, contempla todos os quesitos apontados pelos dispositivos como fundamentais.

Nos textos de Serrano, forma e conteúdo parecem destacar-se como os grandes eixos da crítica. As observações, todavia, no momento da composição, misturam comentários sobre gramática e expressão - forma - com as indicações sobre omissões, exageros e erros crassos em matéria de datas, indicação de lugares, personagens e divergência de interpretação - conteúdos. 


\section{Quadro n. 1}

\section{Relação das obras de História do Brasil e de História da Civilização examinadas por Jonathas Serrano, no âmbito da Comissão Nacional do Livro Didático - 1941}

\begin{tabular}{|c|c|c|c|}
\hline & Obra examinada & Autor & $\begin{array}{l}\text { Data do } \\
\text { parecer }\end{array}$ \\
\hline 1 & História da civilizução (2a série). Recife: Livraria Universal, 1939 & $\begin{array}{l}\text { Estêvão de Meneses } \\
\text { Ferreira Pinto }\end{array}$ & $27 / 031941$ \\
\hline 2 & História do Brasil ( $5^{\text {a }}$ série). S. P.: Edições e Publicações Brasil, 1940.360 p. v. 1. & Alfredo Gomes & 08/04/1941 \\
\hline 3 & História do Brasil (4a série). S. P.: Edições e Publicações Brasil, 1940. 300 pp. & Alfredo Gomes & $31 / 05 / 1941$ \\
\hline 4 & História da civilização ( $1^{\circ}$ ano ginasial). São Paulo: s.n., 1941. & Joaquim Silva & $31 / 05 / 1941$ \\
\hline 5 & História da civilização ( $2^{\circ}$ ano ginasial). S. P.: Companhia Editora Nacional, 1941. & Joaquim Silva & 19/08/1941 \\
\hline 6 & História da civilizcçcio (1ª́rie). São Paulo: Companhia Editora Nacional, 1937. & Estêvão Pinto & 27/08/1941 \\
\hline 7 & $\begin{array}{l}\text { História da civilização ( } 4^{\circ} \text { ano ginasial). } 13 \text { ed. São Paulo: Companhia Editora } \\
\text { Nacional, } 1941 .\end{array}$ & Joaquim Silva & $29 / 09 / 1941$ \\
\hline 8 & $\begin{array}{l}\text { História da civilização ( } 3^{\circ} \text { ano ginasial). } 15 \text { ed. São Paulo: Companhia Editora } \\
\text { Nacional, s.d. }\end{array}$ & Joaquim Silva & $18 / 10 / 1941$ \\
\hline 9 & História do Brasil. 19 ed. São Paulo: companhia Melhoramentos, s.d. & Rocha Pombo & $09 / 1291941$ \\
\hline 10 & $\begin{array}{l}\text { Pontos de bistória do Brasil para uso dos grupos escolares e escolas singulares II, } \\
\text { Ill e IV anos. [Belo Horizonte]: Paulo Azevedo, s.d. }\end{array}$ & Carlos Góis & $18 / 12 / 1941$ \\
\hline 11 & História da civilização (3a série). 3 ed. Rio de Janeiro: J. R. de Oliveira, 1941. & $\begin{array}{l}\text { Azevedo Corrêa e Abdias } \\
\text { Silva }\end{array}$ & $23 / 12 / 1941$ \\
\hline 12 & Não identificada (Processo n. 13.373-39) & Não identificado & $16 / 12 / 1941$ \\
\hline
\end{tabular}

Fonte: Pareceres de Jonathas Serrano. Arquivo Nacional, Fundo Jonathas Serrano, cx. n. 9.

Tabela 1

Estatística dos equivocos identificados por Jonathas Serrano nos livios didáticas de Hisitoria do Brasil e História da Civilização, submetidos à Comissão Nacional do Liwro Didażico no ano de 1941

\begin{tabular}{|c|c|c|c|c|c|c|c|c|c|c|c|}
\hline \multirow{2}{*}{ Equívocos identificados } & \multicolumn{11}{|c|}{ Obras analisadas/Pareceres emitidos } \\
\hline & 1 & 2 & 3 & 4 & 5 & 6 & 7 & 8 & 9 & 10 & 11 \\
\hline Grafia dos nomes próprios e estrangeiros & 1 & & 7 & & & 7 & 15 & 9 & & & \\
\hline Grafia em geral & 13 & 4 & & 1 & 6 & & 1 & 7 & 3 & & \\
\hline Impropriedade vocabular & 3 & 2 & & 1 & 2 & & & & & & \\
\hline Cacofonia & & 3 & & & & & & & & & \\
\hline Acentuação & & 5 & & 1 & 1 & 1 & & 1 & & & \\
\hline Neologismo & & 2 & & & & & & & & & \\
\hline Concordância nominal & & 2 & & & & 1 & & & & & \\
\hline Coloquialismo & & 2 & & & & & & & & & \\
\hline Uso da vírgula & & 1 & & & & & & & & & \\
\hline Flexão verbal & & 1. & & & & & & & & & \\
\hline Construção/sintaxe & & & 1 & & & & & & & & \\
\hline Cumprimento do programa oficial & & & & & & & & & 1 & & \\
\hline Estilo & & 1 & & & & 1 & & & 1 & 1 & 2 \\
\hline Papel, encadernação, impressão & & & & & 1 & & & & & 1 & \\
\hline Metodologia, didática e psicologia & 1 & 1 & & 2 & & & & & & 1 & 1 \\
\hline Indefinição da linguagem (discente/docente) & & & & & & & & & & 1 & \\
\hline Incorporação da pesquisa histórica & & & & & & & & & & & 1 \\
\hline Conteúdo & & 2 & 1 & 3 & 1 & 5 & & 6 & 1 & 2 & \\
\hline
\end{tabular}

Fonte: Pareceres de Jonathas Serrano. Arquivo Nacional, Fundo Jonathas Serrano, cx. n. 9. 
Com alguma paciência, poderemos agrupar os itens acima em cinco categorias e identificar os erros mais recorrentes ou, pelo menos, a quantidade de intervenções de Jonathas Serrano no ato de julgamento de cada obra e no total acumulado durante 0 ano de 1941: incorreção da linguagem $(72,7 \%)$, omissões, exageros e equívocos em termos de conteúdos históricos (15,4\%), problemas metodológicos e didáticos - a expressão é do próprio Serrano $(4,9 \%)$, inadeqüabilidade de estilo da linguagem $(4,2 \%)$, deficiências materiais e tipográficas $(1,4 \%)$.

Comecemos pelo grupo mais numeroso de incorreções apontadas: as questões de gramática. Serrano não perdoa os problemas de acentuação, concordância nominal, flexão verbal, o uso da vírgula e da grafia em geral. Mas, o desleixo ou a ignorância sobre a perfeita forma de comunicar os nomes de autores, personagens, notadamente aqueles de origem estrangeira, é talvez, a falta mais grave a ser considerada. A merecida atenção pode estar relacionada ao seu empenho em normatizar esse tipo de escrita - trabalho inserido em seu Como se ensina história (1936).

o desprezo com a língua-mãe no que diz respeito ao emprego de neologismos, de metáforas descabidas ("período gangrenoso da monarquia") e aos parágrafos mal construídos também são alvo das críticas do professor. Esse trecho do parecer sobre a primeira edição da História do Brasil, de Alfredo Gomes, demonstra bem a sutileza de Serrano, ao fazer troça da escrita do didático:

0 autor emprega várias vezes o vocábulo independentista (ps. II e 14) que em geral não figura nos léxicos. Usa de carestias no plural (p. 122) e de têrmos quais despistar (23) e dupla (320) tirados da linguagem familiar ou popular.

Parece aceitar a construção instalar-se-ia fábricas (p. 24). Refere-se a distâncias agudas, o que mesmo no figurado é estranhável. Emprega o têrmo abspotismo (p. 19), que não conhecemos na linguagem comum. A revisão é péssima no que se refere a vírgulas e só a p. 18 bastaria para exemplificar. (passim).

Deve ser ainda lapso de revisão não incluido na Errata a seguinte forma verbal de frase da página 169: "0 minisério Rio Branco interviu tambem na chamada questão epíscopo-maçônica." (SERRANO, Processo n. 38.524-40, NA/JS, cx. 9 , grifos do autor). 
Além das questões gramaticais e de uso inadequado da língua, o relator faz considerações sobre as formas de construção do parágrafo que resvalam numa avaliação do estilo das obras. Assim, o mesmo Alfredo Gomes foi hiperbólico, Carlos Góis possuía um estilo "curioso" (?) e na obra de Azevedo Corrêa e Abdias Silva faltava clareza, havendo laconismos em demasia que dificultavam a compreensão por parte dos alunos.

A palavra estilo não significa apenas uma certa forma de escrever, uma marca do autor. Estilo também representa uma classificação sobre 0 gênero. Daí, a possibilidade de estar a obra vazada em "estilo didático" ou não. Esse critério pesou bastante na decisão de negar a autorização para que a História do Brasil (19a edição), de Rocha Pombo, fosse utilizada na escola secundária.

Pelos erros, infere-se que a didaticidade do manual dependeria da configuração material, da sua estrutura - existência de quadros sinópticos, por exemplo - e não somente da correção gramatical ou do adequado emprego da língua. 0 bom didático estaria ligado à boa proporção dos tipos, à qualidade do papel, encadernação e impressão, ao uso correto do itálico e ao aparato iconográfico selecionado. Vejamos esse trecho correspondente aos Pontos de bistória do Brasil, de Carlos Góis:

Trata-se de simples opúsculo, de aspecto material paupérrimo, impressão desagradável em mau papel, sem uma única ilustração, retrato ou mapa, bastante só pela pobreza e nenhum atrativo de apresentação para tornar tedioso, senão detestável, o estudo da disciplina. Não se sabe aliás a que espécie de leitores se destina propriamente a obra, se aos discentes ou docentes, pois o ponto $1^{\circ}$ explica o que se deve entender como cousas antigas da localidade, mas de modo geral e abstrato, sem nenhum exemplo concreto. 0 ponto $2^{\circ}$ é uma enumeração, por ordem alfabética, das sedes de municípios, cidades e vilas, inclusive as criadas pela Lei n. 843 de 7 de Setembro de 1923. É uma espécie de Dicionário corográfico, que abrange 38 páginas, com inúmeras datas, decretos, anedotas e lendas históricas. Não há porém, (insistimos nesta observação), nenhum retrato, gravura, mapa ou qualquer recurso iconográfico. Aridez absoluta e desalentadora. (SERRANO, 1941, Processo 7.460/39, AN, cx n. ..., grifos do autor). 
Quanto às questões "metodológicas", releva-se a obediência poderíamos dizer - a alguns princípios pedagógicos: 1) atentar para a coerência da linguagem destinada aos alunos - 0 emprego das mesmas formas de construção do começo ao fim do livro; 2) evitar os erros de linguagem para que os alunos não os reproduzam com certos; 3 ) advertir ao professor para que ele estabeleça a "dosagem" de certos assuntos - como por exemplo, manipular os fatos da pré-história (para as duas séries iniciais do ginásio) - "de acordo com 0 respectivo nível mental"; 4) obedecer às "instruções metodológicas" da Reforma de 1931, que tratam da didática aplicada ao ensino de história da civilização. Esse último tópico, é talvez o maior problema de psicologia/ pedagogia encontrado nos didáticos do período. Serrano explica:

As instruções pedagógicas que acompanham os programas oficiais expedidos, em 30 de junho de 1931, pelo Srn. Ministro de Estado da Educação e Saúde Pública, na parte referente à História da Civilizaçã̃o recomendam: "nas duas séries iniciais do curso, ter-se-á presente que o aluno não possui, via de regra, capacidade para entregar-se a estudos mais abstratos e sistemáticos. É por isso aconselhável, particularmente na primeira série, a história biográfica e episódica, que apresentará, afim de melhor despertar o interesse, os acontecimentos de História geral ligados à vida dos grandes homens.

Padece o livro do Snr. Professor Joaquim Silva do defeito comum a quasi todos os compêndios existentes em português e escritos especialmente para a primeira série, após a reforma Francisco Campos, não obstante as instruções precitadas e de modo particular o trecho acima transcrito. Limitam-se os autores a escrever um resumo elementar da matéria que vai ser depois mais desenvolvida nas séries seguintes de $2^{\mathrm{a}} \mathrm{a} 5^{\mathrm{a}}$ do curso fundamental do ensino secundário. É evidente a não observância das recomendações de caráter metodológico e didático a que nos referimos. (SERRANO, 31 mai. 1941, AN, EJS, cx. n. 9)

Os erros são graves e, na avaliação de Serrano, não há meias palavras. Mas, quando trata dos problemas de conteúdo, a sua ironia se derrama ainda mais. Desses, há vários tipos: da omissão, passando pela troca, adulteração, exagero no tratamento das datas, dos nomes dos personagens, lugares e episódios, até a elaboração de hipóteses pouco lógicas. Somente dois pareceres 
não fazem referência a esse tipo de incorreção.

0 erro mais comum é a troca ou incoerência de datas - um problema que pode ter origem na fabricação do impresso - ano 771 em lugar de 711, por exemplo. Serrano exige precisão: a batalha de Crécy ocorreu em 1346 e não 1347. Mas, eximir a responsabilidade de determinado autor quando este anuncia que a idade mínima para 0 aparecimento do homem foi de 100.000 anos, aí é pedir demais..., segundo o professor.

Não incorporar a pesquisa histórica de ponta é também outro problema notado. 0 parecerista reclama que a maioria dos compêndios tem exagerado em relação aos "efetivos bárbaros" e sugere leituras: "já é tempo que se reduzam [os dados sobre os povos bárbaros] às justas proporções, de acordo com os trabalhos de Ferdinand Lot e outros mestres". Serrano também informa sobre a recente localização da batalha do ano 454: ocorreu entre "Orléans e Troyes e não deve mais ser nomeada de "Campus Mauriacus". A nacionalidade de Colombo está mais que provada. Não há por que duvidar sobre a sua "genovesidade".

Serrano também aponta algumas poucas omissões, o nome da sede do governo egípcio - Memfis. Mas, o que determina a reprovação de uma obra é mesmo a exclusão da história contemporânea do Brasil, relativa ao período $1920 / 1940$.

Outros problemas, como o excesso de minúcias, a seleção "infeliz" de "leituras" sobre Joana D’Arq, bem como da ciência moderna incomodaram ao crítico. Isso, porém, não bastou para desautorizar a circulação das obras. 0 que ocorreu, no máximo, foi uma ironia destilada ao se deparar com afirmações do tipo: os negros maometanos no Brasil adoravam Alá, Olurunuluá (sic) e Mariana - "mãe de Deus, eram, portanto, semimonoteístas (sic)," ou ainda, que Tiradentes teria exercido, simultaneamente, as funções de soldado, mascate, dentista, médico, cirurgião, mineiro e enfermeiro.

Mas, Serrano nunca elogia os pontos positivos? Isso é raro. Um exemplo: ele felicitava-se quando determinado texto corrige omissões dos programas de história estabelecidos pelo Ministério. Ele regozijava-se quando determinado autor tingia a sua obra de "sadio patriotismo". Ele envaidecia-se quando seus livros eram, de alguma forma, empregados como modelo. Mas, denunciava, e com bastante sarcasmo, quando deturpavam as suas orientações.

0 balanço final dos seus relatórios, não obstante os reparos listados 
acima, é bastante positivo para os autores e editores de livros didáticos de história daquele período. Pode-se dizer que o parecerista não era muito ruim de nota. Dos doze relatórios examinados, houve apenas duas reprovações: uma pela quase total ausência dos requisitos didáticos (linguagem adequada, imagens etc.), pela não observância dos programas oficiais; e outra pela omissão da história contemporânea, a história do Brasil dos anos 1920 e 1930.

Em relação ao trabalho final da CNLD, no ano de 1941, a Comissão de História da qual Serrano fazia parte, examinou vinte e três livros. Isso indica que 0 professor foi responsável por metade dos pareceres (52\%) e a maioria deles sobre o ensino secundário. Naquele mesmo ano, um total de mil oitocentas e dezoito obras foram apresentadas para análise. Desse número, apenas quatrocentas e noventa e seis foram examinadas. À comissão de história foi remetido um dos menores conjuntos. Comparando-se com a atividade das demais comissões, pode-se dizer que uma das menores taxas de reprovação coube aos livros de história, posto que a Comissão de Ciências Naturais recebeu cento e trinta e três obras e recusou noventa e oito, resultando uma reprovação de 71\%; a de Filosofia, Sociologia e Pedagogia recebeu trinta e cinco e reprovou vinte e dois (63\%); a de Matemática e Desenho acolheu oitenta e quatro e recusou cinqüenta e três (63\%); Línguas e Literaturas recebeu sessenta e cinco e reprovou trinta e três $(53,5 \%)$; enquanto a de História foram apresentadas vinte e três e recusadas apenas cinco (21,7\%).

Esse breve exame dos pareceres de SERRANO, além de descrever os elementos responsáveis pela didaticidade do livro de história, fornece apenas uma representação do que seria, segundo a ótica do professor, a escrita historiográfica voltada para o ensino secundário no período posterior à reforma Francisco Campos. Pelos números anunciados acima, pode-se conjeturar que o filtro da União não era tão espesso ou ainda, que havia um certo grau de homogeneidade nos processos de produção do livro de história, e que o número de produtores nacionais habilitados (autores e editores) para a tarefa foi bastante reduzido no período. Essas hipóteses e representações podem alcançar um outro patamar de certeza se se puder analisar os dez pareceres restantes, os quais supomos não tiveram Serrano como responsáveis. Outra providência reveladora seria comparar os comentários de Serrano e 0 exame das próprias obras submetidas à CNLD para saber em que medida a obra pedagógica e 
didática do crítico do Pedro II serviu como parâmetro de análise e, em seguida, relacionar o inventário dos acertos ou, na própria expressão de Serrano, o inventário dos momentos em que os autores/editores demonstraram um "louvável senso pedagógico" e se aproximaram da "precisão e serenidade da forma propriamente cientifica". Este, porém, é trabalho para ser desenvolvido em outra ocasião.

\section{Referências}

ALVES, Oscar Rodrigues. Relatório apresentado ao Exmo. Snr. Dr. Altino Arantes, presidente do Estado, pelo Secretário do Interior, Oscar Rodrigues Alves - ano de 1917. São Paulo: Estado de São Paulo/Secretaria do Interior, [1918]. p. 31-32.

ALVES, Oscar Rodrigues. Relatório apresentado ao Exmo. Snr. Dr. Altino Arantes, Presidente do Estado, pelo Secretário do Interior, ano de 1916. São Paulo: s.n., 1917. p. 22.

ANTUNHA, Heládio César Gonçalves. A instrução na primeira República (segunda parte): a União e o ensino secundário na primeira República. São Paulo, 1980, 271 p. Tese (Professor Titular de Metodologia do Ensino e Educação Comparada) - Faculdade de Educação, Universidade de São Paulo.

CARDIM, Carlos Alberto Gomes; MORAIS, Teodoro Rodrigues de; e CARNEIRO JÚNIOR, Miguel. Parecer apresentado ao Exm. Snr. Secretário do Interior pela Comissão incumbida de rever a lista de obras adotadas no curso preliminar. São Paulo, 27 de fevereiro de 1908. In.: RODRIGUES, João Lourenço; DORDAL, Ramon Roca; BARRETO, René; e SILVA, José Carneiro da (orgs.). Anuário do ensino do Estado de São Paulo - 1907/1908. São Paulo: Inspetoria Geral do Ensino, Governo do Estado, [1908]. p. 383-393.

CHINA, João B. C. Relatório do inspetor. In: Anuário do Estado de São Paulo - 1913. São Paulo: Tipografia Siqueira, 1913. p. cxii-cxix.

DÓRIA, Sampaio; MOURA, Américo; BARRETO, Plínio. Relatório da Comissão. In: Estado de São Paulo - Secretaria do Interior - Relatório apresentado ao Exmo. Snr. Dr. Altino Arantes, presidente do Estado, pelo Secretário do Interior, Oscar Rodrigues Alves - ano de 1917. São Paulo: s.n, [1918]. p. 31-32.

FREITAS, Itamar. A história universal de José Estácio Correia de Sá e Benevides (1890/ 1903). In: Histórias do ensino e da bistória. São Cristóvão: Editora da UFS; Aracaju: Fundação Oviêdo Teixeira, 2005. p. 169-224. (no prelo). 
HOLLANDA, Guy de. Um quarto de século de programas e compêndios de bistória para o ensino secundário brasileiro: 1931/1956. Rio de Janeiro: INEP - Ministério da Educação e Cultura, 1957.

REIS JÚNIOR, João Crisóstomo. Relatório do Diretor Geral da Instrução Pública ao Secretário do Interior, em 15 de maio de 1915. Anuário do Estado de São Paulo - 1914. São Paulo: Tipografia Siqueira, 1914. p. 24-25.

Relação das obras apresentadas à Diretoria Geral da Instrução Pública para serem submetidas à aprovação. Relatório apresentado ao Exmo. Snr. Dr. Altino Arantes, Presidente do Estado, pelo Secretário do Interior, Oscar Rodrigues Alves, ano de 1916. São Paulo: s.n., 1917. p. 35-43.

SERRANO, Jonathas. Parecer sobre o livro História da civilização (2a série). Recife: Livraria Universal, 1939, de Estêvão de Meneses Ferreira Pinto, emitido em 27/031941. (Arquivo Nacional, Fundo Jonathas Serrano, caixa n. 9).

Parecer sobre o livro História da civilização ( $1^{\circ}$ ano ginasial). São Paulo: s.n., 1941, de Joaquim Silva, emitido em 31/05/1941. (Arquivo Nacional, Fundo Jonathas Serrano, caixa n. 9).

Parecer sobre o livro História da civilização ( $2^{\circ}$ ano ginasial). São Paulo: Companhia Editora Nacional, 1941, de Joaquim Silva, emitido em 19/08/1941. (Arquivo Nacional, Fundo Jonathas Serrano, caixa n. 9).

. Parecer sobre o livro História da civilização ( $1^{\mathrm{a}}$ série). São Paulo: Companhia Editora Nacional, 1937, de Estêvão Pinto, emitido em 27/08/1941. (Arquivo Nacional, Fundo Jonathas Serrano, caixa n. 9).

. Parecer sobre o livro História da civilização ( $4^{\circ}$ ano ginasial). 13 ed. São Paulo: Companhia Editora Nacional, 1941, de Joaquim Silva, emitido em 29/09/ 1941. (Arquivo Nacional, Fundo Jonathas Serrano, caixa n. 9).

. Parecer sobre o livro História da civilização ( $3^{\circ}$ ano ginasial). 15 ed. São Paulo: SERRANO, Jonathas. Parecer sobre o livro Companhia Editora Nacional, s.d., de Joaquim Silva, emitido em 18/10/1941. (Arquivo Nacional, Fundo Jonathas Serrano, caixa n. 9).

. Parecer sobre o livro História da civilização ( $3^{\mathrm{a}}$ série). 3 ed. Rio de Janeiro: J. R. de Oliveira, 1941, de Azevedo Corrêa e Abdias Silva, emitido em 23/12/1941. (Arquivo Nacional, Fundo Jonathas Serrano, caixa n. 9).

. Parecer sobre o livro História do Brasil ( $4^{\mathrm{a}}$ série). São Paulo: Edições 
e Publicações Brasil, 1940. 300 pp., de Alfredo Gomes, emitido em 31/05/1941. (Arquivo Nacional, Fundo Jonathas Serrano, caixa n. 9).

- Parecer sobre o livro História do Brasil ( $5^{\mathrm{a}}$ série). São Paulo: Edições e Publicações Brasil, 1940. 360 p. v. 1, de Alfredo Gomes, emitido em 08/04/1941. (Arquivo Nacional, Fundo Jonathas Serrano, caixa n. 9).

. Parecer sobre o livro História do Brasil. 19 ed. São Paulo: companhia Melhoramentos, s.d., de Rocha Pombo, emitido em 09/1291941.

Parecer sobre o livro Pontos de bistória do Brasil para uso dos grupos escolares e escolas singulares II, III e IV anos. [Belo Horizonte]: Paulo Azevedo, s.d., de Carlos Góis, emitido em 18/12/1941. (Arquivo Nacional, Fundo Jonathas Serrano, caixa n. 9).

Parecer sobre obra de título e autor não identificados (Processo n. 13.373-39), emitido em 16/12/1941. (Arquivo Nacional, Fundo Jonathas Serrano, caixa n. 9).

SILVA, Geraldo Bastos. A educação secundária: perspectiva histórica e teoria. São Paulo: Companhia Editora Nacional, 1969.

THOMPSON, Oscar. Relatório apresentado ao Exmo. Sr. Dr. Secretário do Interior. In.: Anuário de Ensino do Estado de São Paulo - 1909/1910. São Paulo: Tipografia do Diário, 1910. p. 3-4. 


\section{The scholar historiography in the Comissão Nacional do Livro Didático: judgment of Jonathas Serrano (1938/1941)}

\section{ABSTRACT}

This article examines routines of the Comissão Nacional do Livro Didático (1941), searching answers for sufficiently recurrent questions in the research on the history of the history of education in Brazil: what it is to be didatic? Which the dominant traces in the historiographic production destined to scholar community? Which the criteria used in the evaluation of the book of the student in the administration of the minister Gustavo Capanema? The analysis object is them judgment of the professor and historian Jonathas Serrano (1885/1944) - cathedratic and profesor of the Colégio Pedro II and the Escola Normal do Distrito Federal and partner of the IHGB -, elaborated in the first year of validity of the related Commission.

Key words: textbook, Comissão Nacional do Livro Didático, education of history, scholar historiographic, Jonathas Serrano, secondary education. 